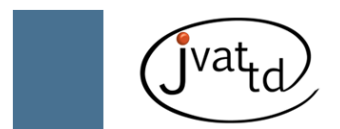

\title{
Preparation and in vitro characterization of chitosan nanoparticles containing Mesobuthus eupeus scorpion venom as an antigen delivery system
}

Mohammadpour Dounighi N (1), Eskandari R (2), Avadi MR (3), Zolfagharian H (1), Mir Mohammad Sadeghi A (3), Rezayat M (2)

(1) Department of Human Vaccine and Serum, Razi Vaccine and Serum Research Institute, Karaj, Iran; (2) Pharmaceutical Sciences Branch, Islamic Azad University, Tehran, Iran; (3) Department of Research and Development, Hakim Pharmaceutical Company, Tehran, Iran.

\begin{abstract}
Hydrophilic nanoparticles have been widely investigated in recent years as delivery systems for therapeutic macromolecules such as antigens. In the present study Mesobuthus eupeus venom-loaded chitosan nanoparticles were prepared via ionic gelation of tripolyphosphate (TPP) and chitosan. The optimum encapsulation efficiency (91.1\%) and loading capacity (76.3\%) were obtained by a chitosan concentration of $2 \mathrm{mg} / \mathrm{mL}$, chitosan-to-TPP mass ratio of 2 and M. eupeus venom concentration of 500 $\mu \mathrm{g} / \mathrm{mL}$. The average nanoparticle size at optimum conditions was determined by Zetasizer (Malvern Instruments, UK). The nanoparticle size was about $370 \mathrm{~nm}$ (polydispersity index: 0.429) while the zeta potential was positive. Transmission electron microscope (TEM) imaging showed a spherical, smooth and almost homogenous structure for nanoparticles. Fourier transform infrared (FTIR) spectroscopy confirmed tripolyphosphoric groups of TPP linked with ammonium groups of chitosan in the nanoparticles. The in vitro release of nanoparticles showed an initial burst release of approximately $60 \%$ in the first ten hours, followed by a slow and much reduced additional release for about 60 hours. It is suggested that the chitosan nanoparticles fabricated in our study may provide a suitable alternative to traditional adjuvant systems.
\end{abstract}

Key words: nanoparticle, chitosan, tripolyphosphate, venom, antigen delivery system, Mesobuthus eupeus.

\section{INTRODUCTION}

Today, nanotechnology is found in a wide range of applications in the pharmaceutical industry (1). Due to new advances in nanotechnology, it is now possible to produce drug nanoparticles that can be utilized in a variety of innovative ways (2).

Injectable nanoparticulate carriers have important potential applications even though conventional carriers can generally be used to reduce the number of administration doses and improve delivery efficiency while decreasing the adverse effects of drug toxicity. In order to achieve this aim, monodispersed biodegradable nanospheres were developed that could be freezedried and easily redispersed, without additives, in aqueous solutions. These drug carriers have been applied in different pharmacological fields (3-5).
One area of interest involves the interactions between nanoparticles and the components of the immune system. Nanoparticles can be designed to either avoid immune system recognition or specifically reduce or enhance the immune responses. Nanoparticle-mediated stimulation and suppression of the immune system can be explained by the fact that manipulation of particle physicochemical characteristics can influence its interaction with immune cells to obtain desirable immunomodulation and avoid undesirable immunotoxicity (6). Moreover, the potential of nanoparticles as an antigen delivery system has been shown in numerous studies $(7,8)$.

Both synthetic and natural polymers were studied with the aim of forming nanoparticles (9). However, among the variety of polymers that were used for drug-loaded nanoparticles, 
chitosan has received great attention in both the medical and pharmaceutical fields (10). Chitosan, a biodegradable and biocompatible polymer, is a modified natural carbohydrate and the second most abundant polysaccharide in nature. It can be synthesized by the partial $\mathrm{N}$-deacetylation of chitin, a natural biopolymer derived from crustacean shells such as crabs, shrimps and lobsters (11). It consists of repeating units of glucosamine and $\mathrm{N}$-acetyl-glucosamine, the proportions of which determine the degree of deacetylation of the polymer (12). Chitosan is available in a wide range of molecular weights and deacetylation degrees. Due to its characteristics, chitosan has gained increasing attention in the pharmaceutical field.

In addition, chitosan presents mucoadhesive, immunostimulating, antimicrobial and woundhealing properties (13-15). Moreover, it has been regarded as a promising polymer for the formulation of vaccine delivery systems. On the other hand, the evaluation of chitosan as an adjuvant for parenteral vaccination studies was reported together with the results of intranasal or oral vaccination studies, making the possible value of chitosan as an adjuvant for parenteral routes less noticeable in the scientific literature. Generally, the design and development of safe novel adjuvants is necessary not only for overcoming the more challenging environment of the mucosal surfaces, but also for vaccination by injection routes, to maximize the efficacy of new or already available vaccines. In the last few years this idea became even more important since newer generations of antigens are predominantly purified recombinant proteins, which often present poor immunogenicity (16).

Chitosan nanoparticles can easily be prepared by the ionic gelation method using TPP as a crosslinking agent. The advantage of this method was attributed to its mild conditions achieved without applying harmful organic solvent, heat or vigorous agitation that are damaging to sensitive proteins. Moreover, it could efficiently retain the bioactivity of macromolecules (such as DNA, proteins, etc.) during preparation (17). It has been reported that chitosan nanoparticles have an excellent capacity for associating proteins (18). CS nanoparticles are widely investigated for delivery of polypeptides such as tetanus toxoid, diphtheria toxoid and snake venom (19-21).

Scorpion venom is rich in various polypeptides with diverse physiological and pharmacological activities (22-24).

The major goal of the current study was to develop a novel antigen delivery system in order to promote the anti-venom manufacturing by improving the hyper-immunization of animals. For this purpose, an effort is being made to prepare new biodegradable nanoparticles for loading of Mesobuthus eupeus scorpion venom and to evaluate their potential as an antigen delivery system.

\section{MATERIALS AND METHODS}

\section{Materials}

Low molecular weight chitosan (48 $\mathrm{kDa})$ derived from shrimp shells (Pandalus borealis), was purchased from Primex Co (Iceland).

The molecular weight of polymer was determined by viscometry (the degree of deacetylation claimed by the supplier was 95\%). Sodium tripolyphosphate (STPP) and coomassie blue G250 were supplied by Sigma (USA). Phosphoric acid (85\%), acetic acid and absolute ethanol were purchased from Merck (Germany).

$M$. eupeus venom was provided in the form of a lyophilized powder by the Razi Vaccine and Serum Research Institute (Karaj, Iran). All other reagents utilized in this study were of analytical grade.

\section{Preparation of Chitosan Nanoparticles and Venom-Loaded Nanoparticles}

Chitosan nanoparticles were synthesized via the ionotropic gelation (25-27) of chitosan with TPP anions. Chitosan was dissolved in acetic aqueous solution at various concentrations (1, $2,3 \mathrm{mg} / \mathrm{mL}$ ). The concentration of acetic acid in aqueous solution was 1.5 time higher than that of chitosan (28). The TPP solution $(1 \mathrm{mg} / \mathrm{mL})$ was prepared by double-distilled water. Chitosan nanoparticles were spontaneously fabricated with the dropwise addition of $5 \mathrm{~mL}$ of the chitosan solution to $2 \mathrm{~mL}$ of TPP solution under magnetic stirring (1000 rpm, 1 hour) at room temperature. The opalescent suspension was formed under the same abovementioned conditions. The nanoparticles were separated by centrifugation at $20,000 \mathrm{~g}$ and $14^{\circ} \mathrm{C}$ for 30 minutes, freeze-dried and stored at $5 \pm 3^{\circ} \mathrm{C}$. The weights of freeze-dried nanoparticles were also measured. 
Venom-loaded nanoparticles were formed by the addition of chitosan solution to TPP solution containing different concentrations of venom. In the present work the effects of venom concentrations $(50,75,100,200,300$ and $500 \mu \mathrm{g} / \mathrm{mL})$ and chitosan concentrations $(1,2,3 \mathrm{mg} / \mathrm{mL})$ on nanoparticle's characteristics have been studied. In order to study one of the abovementioned parameter, the other parameters remained constant.

\section{Characterization of Chitosan Nanoparticles}

The morphological characteristics of nanoparticles were investigated by transmission electron microscope (TEM) (Philips $400^{\circ}, 80 \mathrm{kV}$, The Netherlands). The samples were immobilized on copper grids and dried at room temperature. Then they were stained with phosphate tungsten acid and examined by TEM. The particle size, size distribution [polydispersity index (PDI)] and zeta potential of particles were measured by Zetasizer (Malvern Instruments, UK), based on the dynamic light scattering (DLS) technique. The structural features of nanoparticles were estimated by FTIR (Fourier transform infrared) (FTIR- $410^{\circ}$ Jasco Colchester, United Kingdom), using $\mathrm{KBr}$ pellets.

\section{Determination of Venom Encapsulation Ef-} ficiency and Loading Capacity of Nanoparticles

Venom-loaded nanoparticles were separated from aqueous suspension by centrifugation at $20,000 \mathrm{~g}$ and $14^{\circ} \mathrm{C}$ for 30 minutes. The supernatant was collected and protein content (free venom) in supernatant was determined by the Bradford protein assay spectrophotometric method at 595 $\mathrm{nm}(29,30)$.

The venom encapsulation efficiency $(A E)$ and loading capacity $(L C)$ of nanoparticles were calculated as follows:

$\% A E=[(A-B) / A] \times 100$

$\% L C=[(A-B) / C] \times 100$

Where $A$ is the total amount of venom, $B$ is the free amount of venom and $C$ is the weight of nanoparticles.

\section{In vitro Release Study}

The particular amount of venom-loaded chitosan nanoparticles was suspended in separate tubes containing equal volumes of $0.2 \mathrm{~mol} / \mathrm{L}$ PBS solution ( $\mathrm{pH} 7.4)$ and incubated by shaking at $37^{\circ} \mathrm{C}$ and $600 \mathrm{rpm}$. At appropriate time intervals
$(1,2,4,6,10,22,34,48,72$ hours) one tube was removed and the sample was centrifuged at $20,000 \mathrm{~g}$ and $14^{\circ} \mathrm{C}$ for 30 minutes. The amount of venom released in the supernatant was measured.

\section{RESULTS AND DISCUSSION}

\section{Physicochemical Characterization of Nano- particles}

In the present study, TEM images have shown the morphological properties and surface appearance of nanoparticles. The nanoparticles have nearly spherical shape, smooth surface and size range of about 150-350 nm (Figure 1).

The respective average diameters, measured by Zetasizer, of chitosan nanoparticles and venom-loaded nanoparticles were approximately $260 \mathrm{~nm}$ and $370 \mathrm{~nm}$. The PDI value of chitosan nanoparticles was 0.219 while that of venomloaded chitosan nanoparticles was 0.429 , thus indicating a narrow and favorable particle size distribution (PDI < 0.5) (Table 1).

In present study the results obtained by Zetasizer revealed that the venom-loaded nanoparticles are larger than the chitosan-TPP ones, possibly due to the high molecular weight and large size of the venom protein molecules, venom surface adsorption during incubation time and negligible elevation of viscosity by venom in the loading process (31). Zeta potential of venom loaded chitosan nanoparticles can greatly influence their stability in suspension by means of electrostatic repulsion between the particles (31). Our results demonstrated respective zeta potentials of chitosan and venomloaded nanoparticles of 50.3 and $44.1 \mathrm{mV}$. These results showed that the venom loading leads to a minor reduction of the particle's zeta potential. It is supposed that the venom engagement with long chain chitosan molecules is not uniform.

Chitosan molecules are likely to adopt a diffuse conformation in the solution because of electrostatic repulsion force existing between amine groups along the molecular chain. The carboxyl groups on the surface of a large protein molecule may form hydrogen bonds with amine groups at certain sites along the chitosan chain, but still maintain a compact 3D structure without diffusing in the relatively acidic solution so as to keep an inner hydrophobic core. Therefore, protein molecule attachment did not sufficiently suppress the positive surface charge of chitosan 

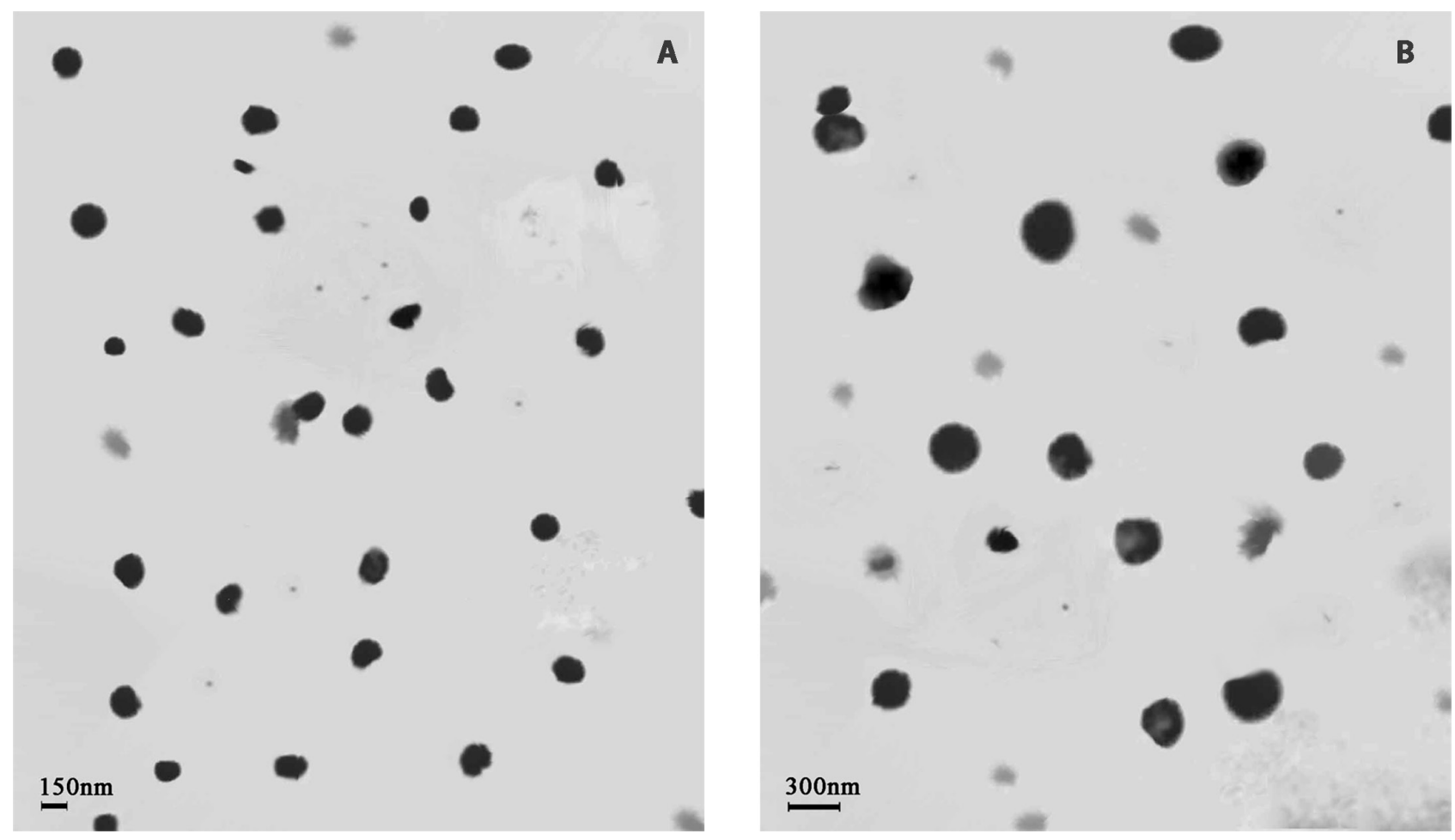

Figure 1. (A) TEM image of chitosan-TPP nanoparticles and (B) M. eupeus venom-loaded chitosan-TPP nanoparticles (chitosan: $48 \mathrm{kDa}, 2 \mathrm{mg} / \mathrm{mL}$; M. eupeus venom $500 \mu \mathrm{g} / \mathrm{mL}$ ).

Table 1. Particle size, polydispersity index and zeta potential of low molecular weight chitosan nanoparticles and venom-loaded chitosan nanoparticles

\begin{tabular}{|c|c|c|c|c|c|c|}
\hline \multirow{2}{*}{$\begin{array}{c}\text { Chitosan } \\
\text { concentration } \\
(\mathrm{mg} / \mathrm{mL})\end{array}$} & \multicolumn{2}{|c|}{ Particle size (nm) } & \multicolumn{2}{|c|}{ Polydispersity index $\left[\left(\mu_{2}\right) / \Gamma^{2}\right]$} & \multicolumn{2}{|c|}{ Zeta potential (mV) } \\
\hline & $\begin{array}{l}\text { Without } \\
\text { venom } \\
\text { loading }\end{array}$ & $\begin{array}{c}\text { Venom- } \\
\text { loaded } \\
\text { nanoparticles }\end{array}$ & $\begin{array}{l}\text { Without } \\
\text { venom } \\
\text { loading }\end{array}$ & $\begin{array}{c}\text { Venom- } \\
\text { loaded } \\
\text { nanoparticles }\end{array}$ & $\begin{array}{l}\text { Without } \\
\text { venom } \\
\text { loading }\end{array}$ & $\begin{array}{c}\text { Venom- } \\
\text { loaded } \\
\text { nanoparticles }\end{array}$ \\
\hline 1.0 & $132 \pm 23.4$ & ND & 0.581 & ND & $54.3 \pm 0.6$ & ND \\
\hline 2.0 & $260 \pm 32.1$ & $370 \pm 34.7$ & 0.219 & 0.429 & $50.3 \pm 2.2$ & $44.1 \pm 0.8$ \\
\hline 3.0 & $300 \pm 17.6$ & ND & 0.170 & ND & $47.2 \pm 1.1$ & ND \\
\hline
\end{tabular}

a Particle preparation conditions: venom concentration $500 \mu \mathrm{g} / \mathrm{mL}$, TPP concentration $1 \mathrm{mg} / \mathrm{mL}, \mathrm{T}: 25 \pm 2^{\circ} \mathrm{C}$. ND: not determined (the physicochemical characteristics of nanoparticles prepared with chitosan concentrations 1 and $2 \mathrm{mg} / \mathrm{mL}$ is not suitable for further study); data shown are the mean \pm standard deviation $(n=3)$.

molecules. There could still be a high proportion of amine group on the chitosan chain which remains unoccupied (31).

The ability of the ionic gelation process to form venom-loaded chitosan nanoparticles was assessed by employing FTIR to determine venom-chitosan interactions. The FTIR spectra of chitosan matrix, chitosan nanoparticles and venom loaded chitosan nanoparticles are shown in Figure 2. In the chitosan spectra, the strong and wide peak in the $3500-3300$ area is attributed to hydrogen-bonded $\mathrm{O}-\mathrm{H}$ stretching vibration. The peaks of $\mathrm{N}-\mathrm{H}$ stretching from primary amine and type II amide are overlapped in the same region (32). The peak for asymmetric stretch of C-O-C is found at around $1150 \mathrm{~cm}^{-1}$ and the peak at 1317 $\mathrm{cm}^{-1}$ belongs to the $\mathrm{C}-\mathrm{N}$ stretching vibration of type I amine. In chitosan-TPP nanoparticles the tip of the peak of $3438 \mathrm{~cm}^{-1}$ has a shift to 3320 $\mathrm{cm}^{-1}$ and becomes wider with increased relative 


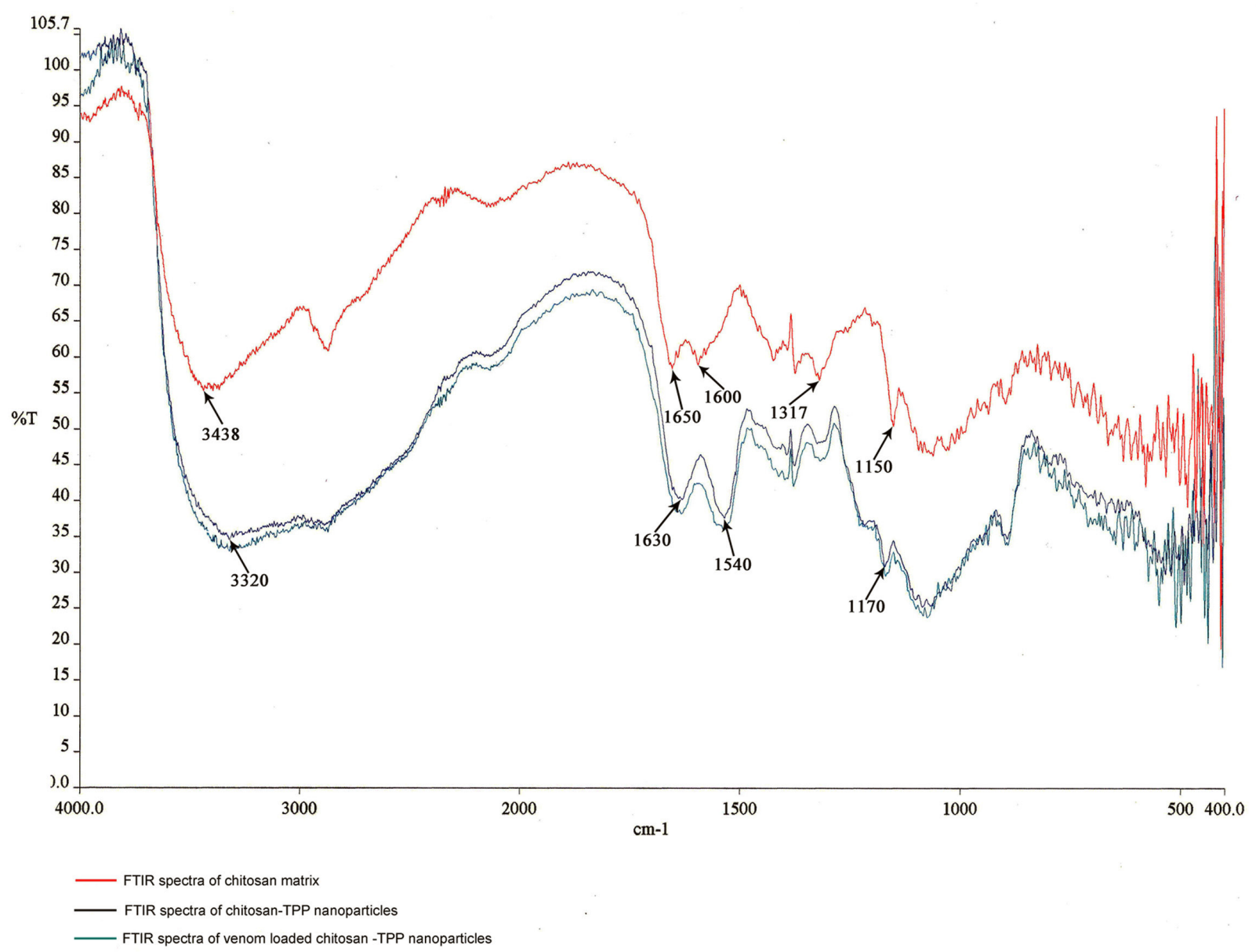

Figure 2. FTIR of chitosan, chitosan-TPP nanoparticles and M. eupeus venom-loaded chitosan-TPP nanoparticles.

intensity indicating an enhancement of hydrogen bonding. In nanoparticles the peaks for $\mathrm{N}-\mathrm{H}$ bending vibration of amine I at $1600 \mathrm{~cm}^{-1}$ and the amide II carbonyl stretch at $1650 \mathrm{~cm}^{-1}$ shifted to $1540 \mathrm{~cm}^{-1}$ and $1630 \mathrm{~cm}^{-1}$, respectively. The crosslinked chitosan also show a $\mathrm{P}=\mathrm{O}$ peak at $1170 \mathrm{~cm}^{-1}$. These results have been attributed to the linkage between phosphoric and ammonium ion. So we conclude that the tripolyphosphoric groups of TPP are linked with ammonium groups of chitosan. The inter- and intra-molecular actions are enhanced in chitosan nanoparticles.

\section{Effect of Chitosan Concentration}

In the present study the effect of different chitosan concentrations $(1,2,3 \mathrm{mg} / \mathrm{mL})$ on nanoparticle formation was evaluated by Zetasizer. Our results showed that by increasing the chitosan concentration from 1 to $3 \mathrm{mg} / \mathrm{mL}$ at a constant TPP concentration $(1 \mathrm{mg} / \mathrm{mL})$, the size of nanoparticles increases (Table 1).
The PDI value of nanoparticles with chitosan concentration of $1 \mathrm{mg} / \mathrm{mL}$ was not within the acceptable range, as shown by the formation of aggregates with large diameters. The PDI value of particles was more favorable at the chitosan concentration of $3 \mathrm{mg} / \mathrm{mL}$ than $2 \mathrm{mg} / \mathrm{mL}$. However, according to the reports on the effect of chitosan/TPP mass ratio on AE and protein release profiles, it can be concluded that a lower chitosan/TPP ratio produces higher overall release and protein encapsulation (33). It has been explained that a lower viscosity of the gelation medium with lower concentration of chitosan results in a decrease in the liquid phase resistance against dispersion, forming smaller nanoparticles and further promoting protein encapsulation (34, 35).

Also it is noteworthy that the molecular weight of chitosan is an important parameter for determining the optimum chitosan/TPP mass ratio $(21,33)$. Therefore, according to our results 
and the abovementioned reports with regard to optimum encapsulation and overall release, it may be suggested that $2 \mathrm{mg} / \mathrm{mL}$ of chitosan and 1 $\mathrm{mg} / \mathrm{mL}$ TPP concentration are suitable for venom loading. So, in an additional study we have used $2 \mathrm{mg} / \mathrm{mL}$ of chitosan and $1 \mathrm{mg} / \mathrm{mL}$ TPP for preparation of venom-loaded nanoparticles.

\section{Effect of Venom Concentration on Loading Capacity and Encapsulation Efficiency}

In the present study the effect of venom concentration $(50,75,100,200,300,500,750$ and $1000 \mu \mathrm{g} / \mathrm{mL}$ ) has been assessed both on encapsulation efficiency and loading capacity. Our data indicate that elevating the venom concentration from 50 to $75 \mu \mathrm{g} / \mathrm{mL}$ leads to a decrease of encapsulation efficiency, while increasing from 75 to $1000 \mu \mathrm{g} / \mathrm{mL}$ results in an increase in loading efficiency (Figure 3). It seems that in lower concentration of venom there is no significant concentration gradient, and the main factor is the electrostatic reactions between polymer and venom. But, at concentrations higher than $75 \mu \mathrm{g} / \mathrm{mL}$, the venom concentration plays a major role in loading (21). As shown in Figure 4, the loading capacity of nanoparticles is increased even more than $100 \%$ at higher venom concentrations (750 and $1000 \mu \mathrm{g} / \mathrm{mL}$ ).

Reports on protein concentration effect on encapsulation are inconclusive and sometimes contradictory. While our findings in this work are in agreement with those of some researchers, they are contrary to $\mathrm{Xu}$ and $\mathrm{Du}(36)$, who reported that the encapsulation results are reversed on bovine serum albumin (BSA) at pH $6.0(20,21,37,38)$. The same trend was also reported by Somnuk J et al. (39) for a-lactalbumin, cytochrome $C$ and ribonuclease A. Since protein molecules are large macromolecules with complex 3D structure and the ability to fold and unfold at different solution conditions, their interactions with long cationic chitosan chains and the consequential encapsulation can be complicated, depending on $3 \mathrm{D}$ conformation, electrostatic and solution conditions. As a crosslinker and condensing agent, TPP forms additional hydrogen bonds with free amine groups on both protein and chitosan molecules, resulting in more compact proteinchitosan nanoparticles. Additional adsorption of protein molecules on the surface of the formed particles may occur in sequence, leading to additional protein loading on the particles (31). Thus, it is suggested that a venom concentration higher than $500 \mu \mathrm{g} / \mathrm{mL}$ is not suitable for this application, because it may lead to additional adsorption of venom on the surface of formed nanoparticles.

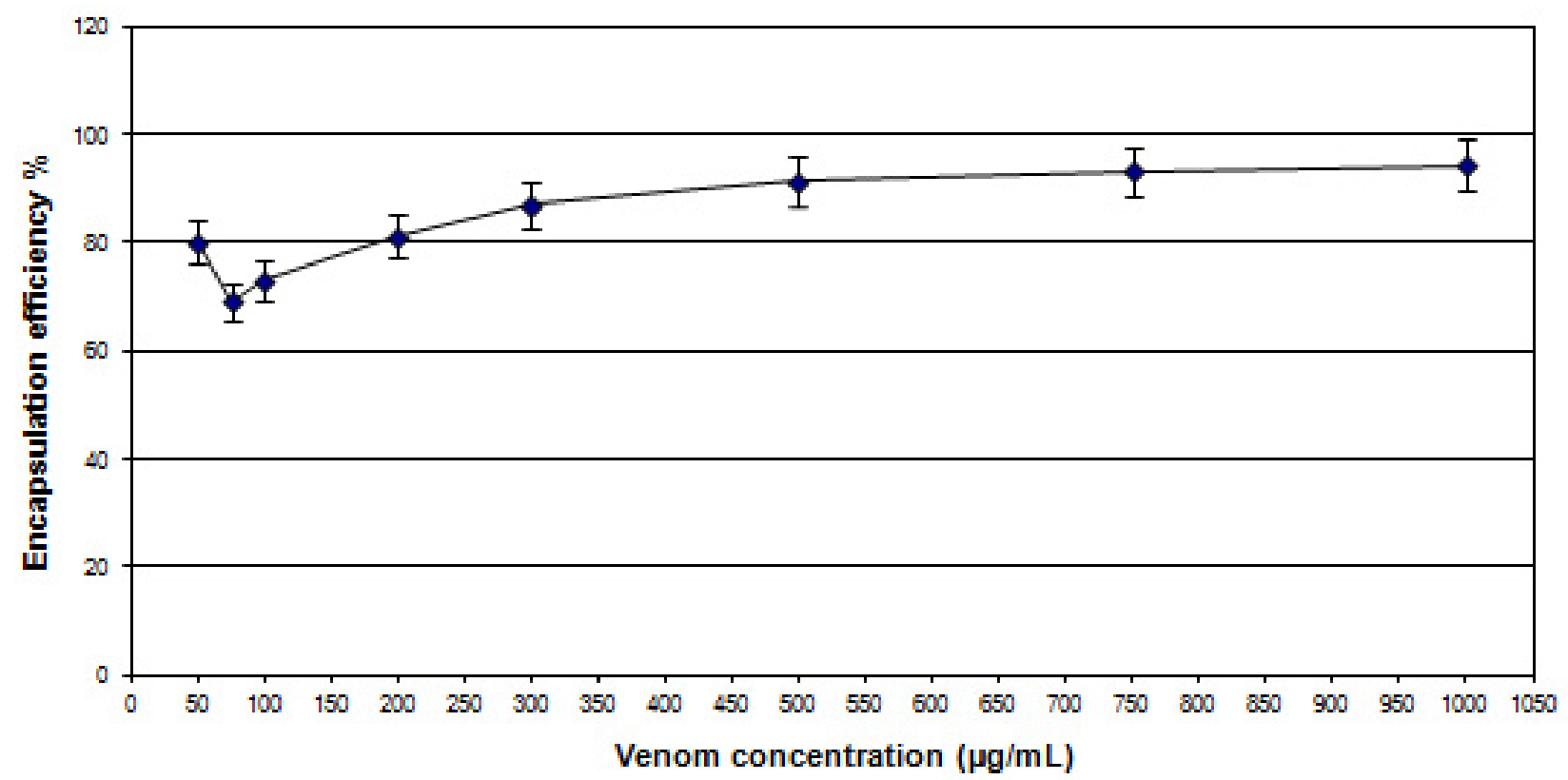

Figure 3. The influence of $M$. eupeus venom initial concentration on encapsulation efficiency (chitosan 2 $\mathrm{mg} / \mathrm{mL}$, TPP $1 \mathrm{mg} / \mathrm{mL}$ ). 


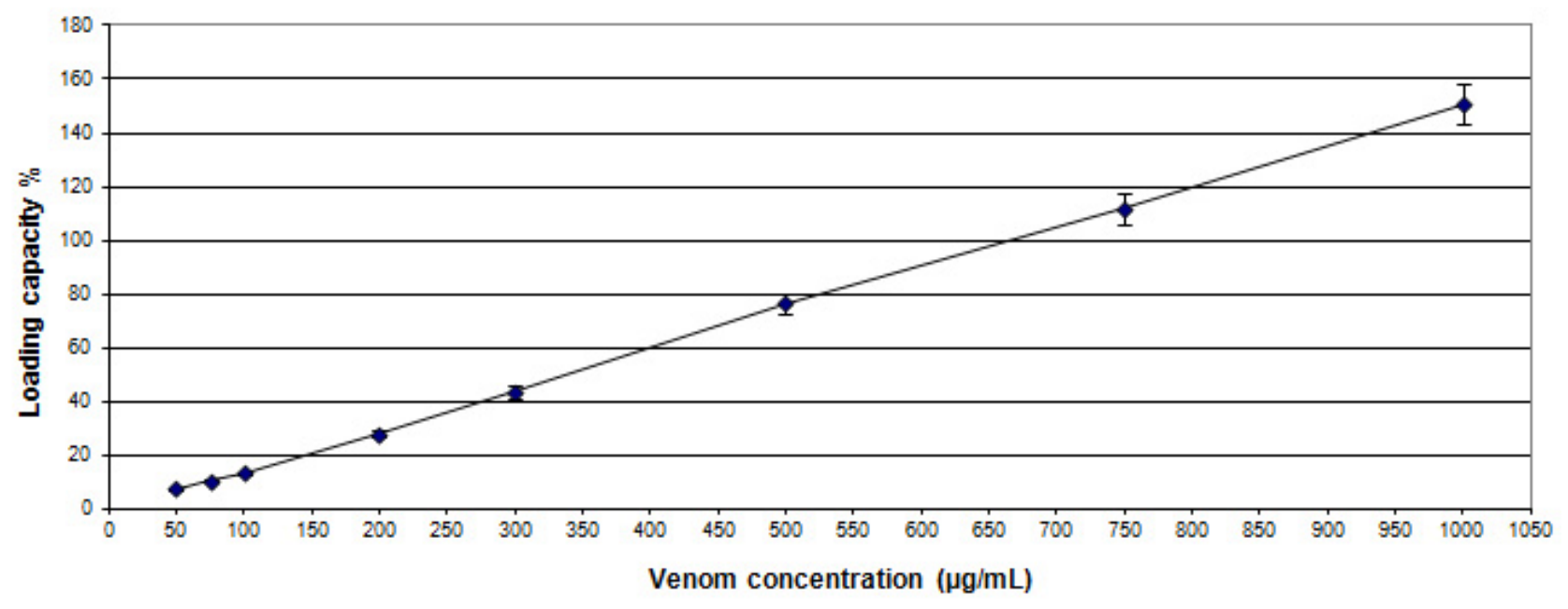

Figure 4. The influence of $M$. eupeus venom initial concentration on loading capacity (chitosan $2 \mathrm{mg} / \mathrm{mL}$, TPP $1 \mathrm{mg} / \mathrm{mL}$ ).

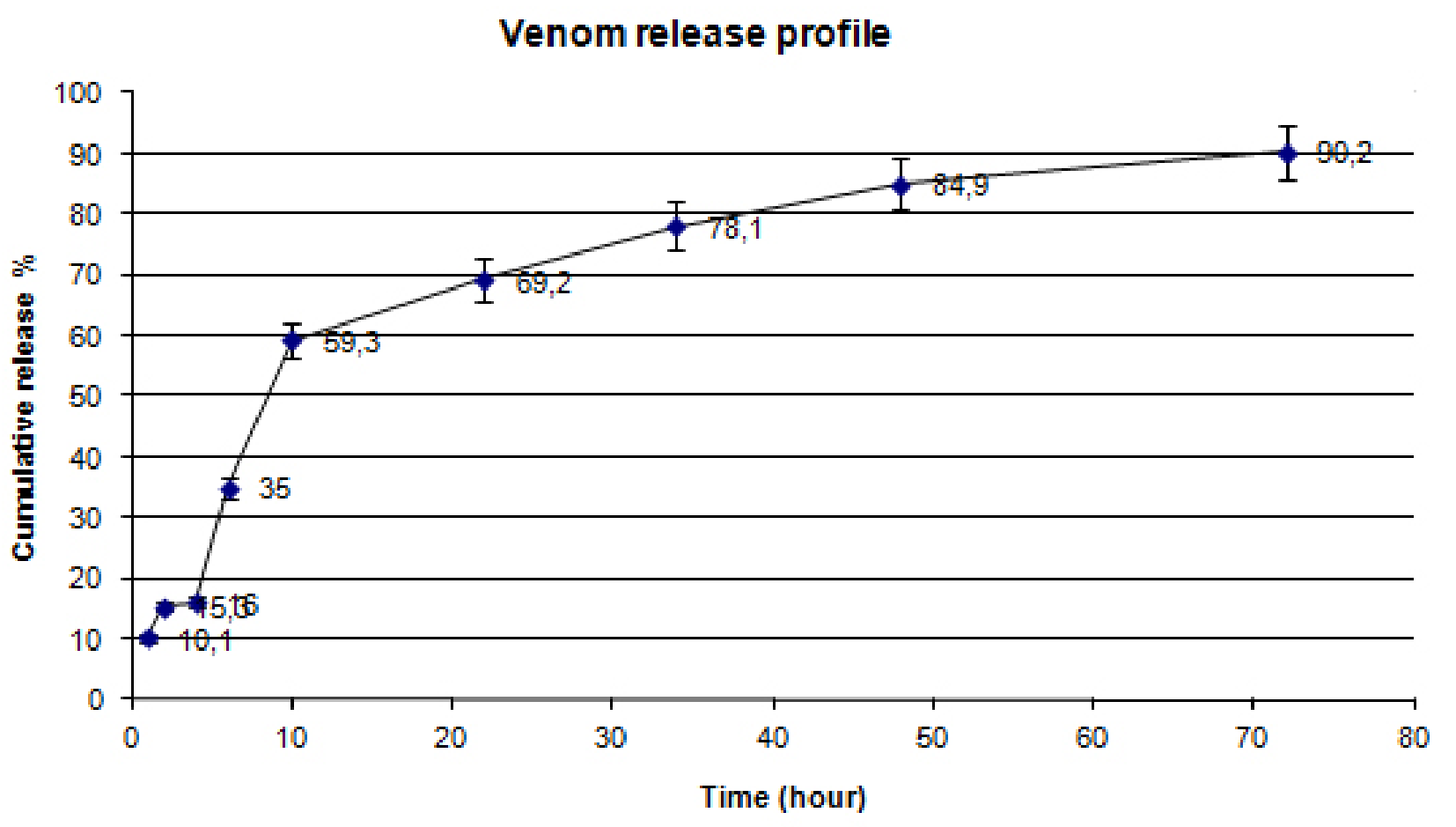

Figure 5. M. eupeus venom release profile from venom-loaded chitosan nanoparticles (chitosan $2 \mathrm{mg} / \mathrm{mL}$, TPP $1 \mathrm{mg} / \mathrm{mL}$, initial M. eupeus venom $500 \mu \mathrm{g} / \mathrm{mL}$, medium pH: 7.4).

\section{In vitro Release Study}

Our observations showed that about $90 \%$ of the loaded venom was released within 72 hours of incubation in PBS. The release profile of venom loaded nanoparticles exhibits an initial burst release of about $60 \%$ in the first 10 hours followed by a slow release of $30 \%$ for the subsequent 62 hours (Figure 5). The observed burst effect was due to dissociation of protein molecules that were loosely bound to the surface of chitosan nanoparticles
(40). In addition, the effect of diffusion of protein molecules dispersing close to the surface of nanoparticles in the first rapid release is undeniable (41). The second part of the release profile is related to the slow release of entrapped protein molecules at an approximately constant rate that arises from the slow degradation of nanoparticles. After 72 hours, the protein degradation rate appears to exceed the release rate (42). 


\section{CONCLUSION}

In this study, chitosan nanoparticles loaded with $M$. eupeus scorpion venom were prepared based on our recently optimized ionotropic gelation method, which employed TPP as the crosslinker to investigate the physicochemical properties of nanoparticles. We used low molecular weight chitosan in our study. The optimum concentrations obtained for chitosan were $2 \mathrm{mg} / \mathrm{mL}$, venom $500 \mu \mathrm{g} / \mathrm{mL}$, TPP $1 \mathrm{mg} /$ $\mathrm{mL}$ and chitosan/TPP ratio 2:1. Under the abovementioned conditions we have prepared venom-loaded nanoparticles with size range of $300-400 \mathrm{~nm}$, loading capacity of $76.3 \%$, encapsulation efficiency of $91.1 \%$ and acceptable PDI. The in vitro release study revealed that the release of venom from chitosan nanoparticles could be better sustained than with conventional venom loaded adjuvants. Therefore, the chitosan nanoparticles prepared in our study appear to be an alternative option to traditional adjuvant systems.

\section{COPYRIGHT}

(C) CEVAP 2012

\section{SUBMISSION STATUS}

Received: June 3, 2011.

Accepted: August 24, 2011.

Abstract published online: August 25, 2011.

Full paper published online: February 28, 2012.

\section{CONFLICTS OF INTEREST}

The authors declare no conflicts of interest.

\section{FINANCIAL SOURCE}

The Razi Vaccine and Serum Research Institute (Karaj, Iran) provided the financial grants.

\section{CORRESPONDENCE TO}

Naser Mohammadpour Dounighi, Razi Vaccine and Serum Research Institute, Postal Code 31987, Karaj, Iran. Phone: +98 261 4502865. Fax: +98 261 4552194. Email: Nasser_mohammadpour@ yahoo.com.

\section{REFERENCES}

1. Gupta RB. Fundamentals of drug nanoparticles. In: Gupta RB, Kompella UB, editors. Nanoparticle Technology for Drug Delivery. New York: Taylor \& Francis group; 2006. p. 1-18.
2. Jain KK. Nanopharmaceuticals. In: The handbook of nanomedicine. Basel, Switzerland: Humana Press; 2008. p. 119-60.

3. Bhattarai N, Ramay HR, Chou SH, Zhang M. Chitosan and lactic acid-grafted chitosan nanoparticles as carriers for prolonged drug delivery. Int $\mathrm{J}$ Nanomedicine. 2006;1(2):181-7.

4. Dustgani A, Farahani EV, Imani M. Preparation of chitosan nanoparticles loaded by dexamethasone sodium phosphate. Ir J Pharm Sci. 2008;4(2):111-4.

5. Gref R, Minamitake Y, Peracchia MT, Trubetskoy V, Torchilin VP, Langer R. Biodegradable longcirculating polymeric nanospherese. Science. 1994;263(5153):1600-3.

6. Zolnik BS, González-Fernandez A, Sadrieh N, Dobrovolskaia MA. Nanoparticles and the immune system. Endocrinology. 2010;151(2):458-65.

7. Sayin B, Somavarapu S, Li XW, Thanou M, Sesardic D, Alpar HO.2008. Mono-N-carboxymethyl chitosan (MCC) and N-trimethyl chitosan (TMC) nanoparticles for non-invasive vaccine delivery. Int J Pharm. 2008;363(1-2):139-48.

8. Waghmare A, Deopurkar RL, Salvi N, Khadilkar M, Kalolikar M, Gade SK. Comparison of Montanide adjuvants, IMS 3012 (Nanoparticle), ISA206 and ISA35 (Emulsion based) along with incomplete Freund's adjuvant for hyperimmunization of equines used for production of polyvalent snake antivenom. Vaccine. 2009;27(7):1067-72.

9. Tiyaboonchai W. Chitosan nanoparticles: a promising system for drug delivery. Naresuan U J. 2003;11(3):5166.

10. Shahbazi MA, Hamidi M, Peymani P. Interaction of chitosan, a natural polymer used in Nanodrug/gene delivery, with non-steroidal anti-inflammatory drugs (NSAIDs). Internet J Nanotech. 2008;2(2).

11. IIIum L. Chitosan and its use as a pharmaceutical excipient. Pharm Res. 1998;15(9):1326-31.

12. Bowman K, Leong KW. Chitosan nanoparticles for oral drug and gene delivery. Int J Nanomedicine. 2006;1(2):117-28.

13. Agnihotri SA, Mallikarjuna NN, Aminabhavi TM. Recent advances on chitosan-based micro- and nanoparticles in drug delivery. J Control Release. 2004;100(1):5-28.

14. Lai WF, Lin CM. Nucleic acid delivery with chitosan and its derivatives. J Control Release. 2009;134(3):15868.

15. Nwe N, Furuike T, Tamura H. The mechanical and biological properties of chitosan scaffolds for tissue regeneration templates are significantly enhanced by chitosan from Gongronella butleri. Materials. 2009;2(2):374-98.

16. Borges $\mathrm{O}$, Silva $M$, de Sousa AD, Borchard G, Junginger HE, Cordeiro-da-Silva A. Alginate coated chitosan nanoparticles are an effective subcutaneous adjuvant for hepatitis B surface antigen. Int Immunopharmacol. 2008;8(13-14):1773-80.

17. Pan Y, Li YJ, Zhao HY, Zheng JM, Xu H, Wei G, et al. Bioadhesive polysaccharide in protein delivery system: chitosan nanoparticles improve the intestinal 
absorption of insulin in vivo. Int J Pharm. 2002;249(12):139-47.

18. Fernández-Urrusuno R, Calvo $\mathrm{P}$, Remuñan-López C, Vila-Jato JL, Alonso MJ. Enhancement of nasal absorption of insulin using chitosan nanoparticles. Pharm Res. 1999;16(10):1576-81.

19. Vila A, Sánchez A, Janes. K, Behrens L, Kissel T, VilaJato JL, Alonso MJ. Low molecular weight chitosan nanoparticles as new carriers for nasal vaccine delivery in mice. Eur J Pharm Biopharm. 2004;57(1):123-31.

20. Rezaei Mokarram A, Alonso MJ. Preparation and evaluation of chitosan nanoparticles containing diphtheria toxoid as new carriers for nasal vaccine delivery in mice. Arch Razi Inst. 2006;61(1):13-25.

21. Mohammadpourdounighi N, Behfar A, Ezabadi A, Zolfagharian H, Heydari M. Preparation of Chitosan nanoparticles containing Naja-naja oxiana snake venom. Nanomedicine. 2010;6(1):137-43.

22. Kadkhodaei-Elyaderani M, Hanifi H, Amozegari Z. Isolation and purification of toxic fractions from the venom of scorpion Mesobuthus eupeus. Urmia Med J. 2007;17(4):349-50.

23. Wudayagiri $\mathrm{R}$, Inceoglu $\mathrm{B}$, Herrmann $\mathrm{R}$, Derbel M, Choudary PV, Hammock BD. Isolation and characterization of a novel lepidopteran-selective toxin from the venom of South Indian red scorpion, Mesobuthus tamulus. BMC Biochem. 2001;2:16.

24. Latifi M, Tabatabai M. Immunological studies on Iranian scorpion venom and antiserum. Toxicon. 1979;17(6):617-20.

25. Kawashima Y, Handa T, Kasai A; Takenaka H, Lin SY, Ando Y. Novel method for the preparation of controlled-release theophylline granules coated with a polyelectrolyte complex of sodium polyphosphatechitosan. J Pharm Sci. 1985;74(3):264-8.

26. Kawashima Y, Lin SY, Kasai A, Handa T, Takenaka H. Preparation of a prolonged release tablet of aspirin with chitosan. Chem Pharm Bull. 1985;33(5):2107-13.

27. Werle $M$, Takeuchi $H$, Bernkop-Schnürch A. Modified chitosans for oral drug delivery. J Pharm Sci. 2009;98(5):1643-56.

28. Xu Y, Du Y. Effect of molecular structure of chitosan on protein delivery properties of chitosan nanoparticles. Int J Pharm. 2003;250(1):215-26.

29. Bradford M. A Rapid and sensitive method for the quantitation of microgram quantities of protein utilizing the principle of protein-dye binding. Anal Biochem.1976;72:248-54.
30. Kruger N. The Bradford method for protein quantitation. Methods Mol Biol. 1994; 32:9-15.

31. Gan Q, Wang T. Chitosan nanoparticles as protein delivery carrier-systematic examination of fabrication conditions for efficient loading and release. Colloids Surfaces B. 2007;59(1):24-34.

32. Yu JH, Du YM, Zheng H. Blend films of chitosangelation. Wuhan Univ J Nat Sci. 1999; 45:440-4.

33. Gan Q, Wang T, Cochrane C, McCarron P. Modulation of surface charge, particle size and morphological properties of chitosan-TPP nanoparticles intended for gene delivery. Colloids Surfaces B. 2005;44(2-3):65-73.

34. Wu Y, Yang W, Wang C, Hu J, Fu S. Chitosan nanoparticles as a novel delivery system for ammonium glycyrrhizinate. Int J Pharm. 2005;295(1-2):235-45.

35. Zhang HL, Wu SH, Tao Y, Zang LQ, Su ZQ. Preparation and characterization of water-soluble chitosan nanoparticles as protein delivery system. J Nanomaterials. 2010;2010:5.

36. Xu Y, Du Y. Effect of molecular structure of chitosan on protein delivery properties of chitosan nanoparticles. Int J Pharm. 2003;250(1):215-26.

37. Berthold A, Cremer K, Kreuter J. Preparation and characterization of chitosan microspheres as drug carrier for prednisolone sodium phosphate as model for anti-inflammatory drugs. J Control Release. 1996;39(1):17-25.

38. Avadi MR, Sadeghi AM, Mohammadpour N, Abedin $\mathrm{S}$, Atyabi F, et al. Preparation and characterization of insulin nanoparticles using chitosan and Arabic gum with ionic gelation method. Nanomedicine. 2010;6(1):58-63.

39. Somnuk J, Anupap T, Virote B. Preparation of chitosan nanoparticles for encapsulation and release of protein. Korean J Chem Eng. 2011;28(5):1247-51.

40. Amidi M, Romeijn SG, Borchard G, Junginger HE, Hennink WE, Jiskoot W. Preparation and characterization of protein-loaded N-trimethyl chitosan nanoparticles as nasal delivery system. J Control Release. 2006;111(1-2):107-16.

41. Zhou SB, Deng XM, Li X. Investigation on a novel core-coated microspheres protein delivery system. J Control Release. 2001;75(1-2), 27-36.

42. Dailey LA, Wittmar M, Kissel T. The role of branched polyesters and their modifications in the development of modern drug delivery vehicles. J Control Release. 2005;101(1-3):137-49. 